|Araştırma Makalesi / Research Article|

\title{
Öğretmen Adaylarının Illk Yardım Bilgi Düzeyleri: Kastamonu Üniversitesi Örneği ${ }^{1}$
}

\section{Pre-Service Teachers' First Aid Knowledge Levels: The Case of Kastamonu University}

\section{Sema İrem Orhan², Abdullah AYDIN ${ }^{3}$}

\begin{tabular}{l} 
Anahtar Kelimeler \\
ilk yardım \\
öğretmen adayı \\
bilgi düzeyi \\
\hline Keywords \\
first aid \\
pre-service teacher \\
knowledge level \\
\hline Başvuru Tarihi/Received \\
16.05.2019
\end{tabular}

Kabul Tarihi /Accepted 20.04.2020

\begin{abstract}
Öz
İlk yardım uygulamaları zamanında tatbik edildiğinde hayat kurtaran pratik uygulamalar olup, ilk yardım müdahalesi gerektiren vakalar yüksek aktivite ve merak duygusuna sahip küçük yaşlardaki bireylerde sıklıkla görülmektedir. Günümüzde henüz her eğitim kurumunda aktif bir sağlık birimi ve görevlisi bulunmadığı gerçeği de göz önünde bulundurulduğunda, öğretmenler söz konusu ilk yardım müdahalelerini yapacak kişiler arasında ilk sırada yer almaktadırlar. Bu doğrultuda araştırmanın amacı, geleceğin öğretmenleri olacak olan ve Kastamonu Üniversitesi, Eğitim Fakültesi'nde öğrenim gören öğretmen adaylarının, ilk yardım bilgi düzeylerinin belirlenmesi ve elde edilen bilgiler ışığında durum hakkında betimleyici çıkarımların ortaya konulmasıdır. Araştırmaya 2038 öğretmen adayı katılmış ve veri toplamak için 30 soruluk bir anket uygulanmıştır. Anketten elde edilen verilere göre öğretmen adaylarının \%96'sı ilk yardım eğitiminin gerekli olduğunu ifade etmişlerdir. Öğretmen adaylarının \%57'si daha önce ilk yardım eğitimi aldığını, bu eğitimi alanların \%69'u ilk yardım eğitimini ders olarak, \%31'i ise ehliyet kursunda aldıklarını ifade etmişlerdir. İlk yardım eğitiminin eğitim fakültelerindeki tüm öğretmenlik programları için zorunlu olması önerilmektedir.
\end{abstract}

\section{Abstract}

When first aid applications are applied on time, they are practical applications that save lives, and first aid intervention is frequently seen in young people with high activity and curiosity. Given the fact that today there is not yet an active health unit and staff in every educational institution, teachers are among the first to be involved in first aid interventions. In this respect, it is aimed to determine the first aid information levels of pre-service teacher who will be teachers of the future in this study and who are studying at Kastamonu University, Faculty of Education and to reveal descriptive conclusions about the situation in the obtained information light. 2038 pre-service teachers participated in the study and a 30 -item questionnaire was used to collect data. According to the questionnaire obtained, $96 \%$ of the pre-service teachers stated that first aid training is necessary. $57 \%$ of the pre-service teacher had already received first aid training, $69 \%$ of them said that this training was given as a course and $31 \%$ of them had received first aid training in the driver's license course. It is recommended that first aid education is compulsory for all teaching programs in education faculties.

\footnotetext{
${ }^{1}$ Bu çalışma, 06-08 Eylül 2018 tarihleri arasında Amasya Üniversitesi'nde düzenlenen, International Learning Teaching and Educational Research Congress (ILTER2018)'de sözlü bildiri olarak sunulmuştur.

${ }^{2}$ Kastamonu Üniversitesi, Fen Bilimleri Enstitüsü, Doktora Öğrencisi, Kastamonu, TÜRKiYE; https://orcid.org/0000-0002-4554-1439

${ }^{3}$ Kastamonu Üniversitesi, Eğitim Fakültesi, Matematik ve Fen Bilimleri Eğitimi Bölümü, Kastamonu, TÜRKiYE; https://orcid.org/0000-0003-2805-9314

Alıntı/Citation: Orhan, S. İ., \& Aydın, A. (2020). Öğretmen adaylarının ilk yardım bilgi düzeyleri: Kastamonu Üniversitesi örneği. Kastamonu Education Journal, 28(4), 1657-1667. doi: 10.24106/kefdergi.3798
} 


\section{Extended Abstract}

\section{Introduction}

First aid applications are defined as practical applications that save lives when applied on time. The incidence of events requiring first aid intervention is more common because of the high activity and curiosity of younger individuals, as well as the inadequate development of cognitive outcome and motor activity abilities. During this age, a large part of the people's daily time is spent in educational environments, and situations that require first aid intervention are more likely to occur within this time frame. Given the fact that today there is not yet an active health unit and staff in every educational institution, teachers are among the first to be involved in first aid interventions. it is aimed to determine the first aid information levels of pre-service teachers who will be teachers of the future in this study and who are studying at Faculty of Education in Kastamonu University and to reveal descriptive conclusions about the situation in the obtained information light.

\section{The significance of the Study}

First aid is needed in schools such as bleeding, respiratory insufficiency, fainting, convulsion, allergic reactions, burns, poisoning, head trauma, upper respiratory tract infections, skin infections, diarrhea, vomiting, abdominal pain, sprains, fractures and dislocations. The emergence of infectious diseases also requires an acute approach (Erkan and Göz, 2006). Accidental accidents can also be experienced in laboratory studies, such as those in service vehicles that provide access to school (West, 1996; Budge, 1998; Kauffman, 2002; Hoff, 2003; Erkan and Göz, 2006). Based on all this information, the aim of this research is to determine the first aid knowledge levels of teachers who are primarily responsible for the health of secondary school students. In this way, it can be revealed what the teachers need to be informed about and the studies to eliminate the deficiencies identified can be initiated.

\section{Method}

The first aid knowledge levels of the pre-service teachers attending the Faculty of Education in Kastamonu University, were collected from the quantitative data collection tools by the questionnaire method and the opinions and opinions of the pre-service teachers. It is possible to determine the opinion of a large sample group on the subject of research. This research is a descriptive study using the screening model. The screening model is a research that aims to describe a situation that has existed in the past or the present. The subject matter of the research is tried to be defined in its own conditions and as it is (Karasar, 2012).

\section{Participants}

Research, computer and instructional technologies education, science education, elementary mathematics education, music education, pre-school education (I and II. teaching), art education, classroom education, social sciences education, Turkish education and guidance and psycho-logical counselling total of 2038 pre-service teachers, including 1443 female and 595 males, who were enrolled teaching programs in Faculty of Education of Kastamonu University, participated as volunteers.

\section{Application Process}

The pre-service teachers who were the participants of the study were reached at the address of https://obs.kastamonu.edu.tr/ in the information system of Kastamonu University. The data were collected by survey method between 23.03 .2018 and 16.04.2018. pre-service teachers were given 30 minutes to answer questions in the questionnaire. It was ensured that the answers given to the pre-service teachers were used for the purpose of the research that no individual evaluation would be made and the forms would not be seen by anyone other than the researchers.

\section{Findings and Comments}

In this section, the findings of the data obtained from the scale applied to pre-service teachers are arranged and interpreted as tables for the purpose of the study. Did you receive first aid training for pre-service teachers in the survey? and do you think you should? The questions are directed and the frequency and percentage values of the answers given to these walls are calculated. $57 \%$ of pre-service teachers stated that they had received first aid training, $43 \%$ had not received it and $96 \%$ had first aid education. $69 \%$ of the pre-service teachers stated that they received first aid training as a course and $31 \%$ of them were on a driving license course. while 1274 (71.53\%) of the female pre-service teachers who participated in the study answered the fourth question with the highest percentage, 507 (28.47\%) of the male pre-service teachers answered the same question at the highest rate. While 171 (68.95) of the female pre-service teachers responded to the minimum number of questions correctly, 77 (31.05\%) of the male pre-service teachers gave the correct answer to the same question. According to the data, female pre-service teachers' first aid knowledge is higher than male pre-service teachers. The first-aid test of pre-service teachers was calculated as $51 \%$. On the basis of teaching program, the success percentages vary between $45 \%$ and $52 \%$. While the lowest success rate was $45 \%$ in the art education program, the most successful teaching program was pre-school education with $55 \%$. 


\section{Results and Discussion}

In this study, it was aimed to determine the first aid information levels of the pre-service teachers studying in the Faculty of Education according to the gender and the program they were studying, and a questionnaire including first aid questions was applied to 2038 pre-service teachers studying at Faculty of Education in Kastamonu University. According to the results, more than half of the pre-service teachers reported that they received first aid education, but their knowledge level was below $50 \%$ in terms of vital critical aspects such as breathing, poisoning, fainting and loss of consciousness, bleeding and limb severity. In addition, $96 \%$ of pre-service teachers stated that initial education was necessary. It is thought that the fact that pre-service teachers who are in the first place among the first aid intervention institutions in education institutions have received first aid education but low information on basic first aid level should be considered carefully. This situation has been mentioned in similar studies (Bozkurt et al., 2015; Erkan and Göz, 2006; Bayraktar and Çelik, 2000; Amro and Qtait, 2017; Gowri and Missiriya, 2017; Karadag-Arli and Yildirim, 2017; Özyürek et al., 2013). It was determined that female pre-service teachers who participated in the study were more successful than male pre-service teachers in terms of first aid knowledge. This difference can be attributed to the fact that women face situations requiring more first aid than men in their daily lives (Saruhan et al., 2018). Nayır, Uskun and Türkoğlu (2011) found that women 's first aid knowledge point averages were significantly higher than men' s first aid knowledge scores. In similar studies, the difference between the knowledge scores of men and women by Koç (1994) and Savaşer (2001) gender was found to be statistically significant in similar studies. Women's knowledge scores are higher than males. The results obtained from this study as well as the results obtained from similar studies in the literature seem to be consistent. As a result of the study, it was determined that pre-service teachers did not have enough information about the first semester and they expressed their educational needs by being aware of these shortcomings. First aid and basic life support training must be compulsory for all teaching pro-grams in the Faculty of Education. In addition, this training should be updated at regular intervals. The first aid lesson taught in schools should provide the students with the basic knowledge and skills to acquire the behaviours related to the objectives stated in the curriculum. 


\section{GiRiş}

İlkyardım, herhangi bir kaza ya da yaşamı tehlikeye düşüren bir durumda sağlık görevlilerinin yardımı sağlanıncaya kadar hayatın kurtarılması ya da durumun daha kötüye gitmesini önleyebilmek amacıyla yapılan uygulamalardır (Kırılmaz ve Arısoy, 2002; Akdemir ve Birol, 2005; Büyükkayacı-Duman, Koçak ve Sözen, 2013). İlk yardım uygulamaları zamanında tatbik edildiğinde hayat kurtaran pratik uygulamalar olarak tanımlanmaktadır. Günümüzde, gelişmiş ve gelişmekte olan ülkelerde kazalar ve yaralanmalar her yaş grubunda özellikle çocukluk çağında önlenebilir sağlık sorunlarının başında gelmekte, ölüm ve engelli yaşam nedenleri arasında ilk sıralarda yer almaktadır (Stone vd., 2000; Kliegman, Behrmen, Jenson ve Stanton, 2007; Bozkurt vd., 2015). Meydana gelen kazalarda ölümlerin \%10'u ilk 5 dakika içerisinde, yarısı ise ilk 30 dakika içerisinde olmaktadır. Yine yapılan araştırmalarda, meydana gelen ölümlerin \%38'inin kaza yerinde yapılan bilinçli ve yeterli ilk yardım uygulamaları sayesinde önlenebileceği tespit edilmiştir. En etkili ilk yardım müdahaleleri ilk 5 dakikada yapılanlardır. Bu bilgiler ışığında, kişilerin ilk yardım konusunda doğru ve yeterli bilgilere sahip olmalarının ne kadar önemli olduğu görülmektedir (Altındiş vd., 2017; Aytaç, Gürleyen-Gök, Özkan, 2016; Lingard, 2002; Singer, Gulle, Thode ve Cronin, 2004). Türkiye'de 2016 yılı trafik kazaları verilerine göre kaza yeri ölü sayısı 3493, kaza sonrası ölü sayısı 3807, yaralı sayısı 303.812'dir (URL-1). Ayrıca Türkiye İstatistik Kurumu (TUiK) verilerine göre; ülkemizde 2016 yılında 15 yaş ve üzeri kişilerde ölüm vakalarının \%4,3’ünü dışsal yaralanma nedenleri ve zehirlenmelerin oluşturduğu görülmektedir. Gençlerde dışsal yaralanma ve zehirlenmeler nedeni ile ölüm oranı \%50,5 olup, bu oran genç erkeklerde \%57,3, genç kadınlarda \%31,8'dir (Kızıl vd., 2018; URL-2).

İlk yardımla ilgili bilgi ve uygulamaların toplumdaki bütün bireylerce bilinmesi arzu edilen bir durumdur. Ancak bunu sağlamak oldukça güçtür (Koç, 1994; Saruhan vd., 2018). Okullarda meydana gelen kazalarda ya da öğrencilerin başına gelen acil durumlarda ya da mevcut hastalığa bağlı gelişebilecek sorunlarda gerekli olan ilk müdahaleyi yapmak öncelikle var olan sağlık personelinin görevidir. Ancak Ülkemizde özellikle devlet okulları başta olmak üzere, pek çok okulda hemşire bulunmamakta, bu görevi okul sağı̆ğı ekibinin bir üyesi olan öğretmenler üstlenmektedir. Bu sebepten dolayı öğretmenin yeterli düzeyde sağlık bilgisiyle donanmış olması çok önemlidir (T.C. Sağlık Bakanlığı, 2008). Okullarda karşılaşılan acil durumlarda sağlık ekibi olay yerine ulaşıncaya kadar ya da çocuk sağlık kurumuna ulaştırılıncaya kadar öğretmenin müdahalesi oldukça önem taşımaktadır (Ateş, 2005). Bununla birlikte, ilk yardım sağlayıcısı durumu hızlı ve sakin bir şekilde değerlendirebilmeli, kendisini tehlikeden korurken hayatı tehdit edici koşullar ile başa çıkabilmeli, tıbbi yardım alabilmeli ve ciddi yaralanma veya hastalık durumunda ambulans çağırabilmelidir (Amro ve Qtait, 2017).

İlk yardım müdahalesi gerektiren olayların görülme sıklığı küçük yaşlardaki çocuklarda daha fazladır. Bunun sebebi, çocukların yüksek aktivite ve merak duygusuna sahip olmalarının yanı sıra bilişsel çıkarım ve motor aktivite yeteneklerinin tam gelişmemiş olmasıdır. Çocukların bu yaş dönemlerinde kişilerin günlük zamanının büyük bir bölümü eğitim ortamlarında geçmekte ve söz konusu ilk yardım müdahalesi gerektiren durumlar da daha çok bu zaman dilimi içinde vuku bulmaktadır. Dünya'da her yıl, her 10 çocuktan biri kaza nedeniyle bir sağlık kuruluşuna başvurmaktadır. Büyüme gelişme, işitme ve görme bozuklukları, ruhsal sorunlar gibi sağlık sorunlarının sık görüldüğü çocukluk ve gençlik dönemi olan okul çağı, 7-14 yaşları içine alan ilk ve ortaokul dönemidir (Beyazova ve Güler, 1991; Erkan ve Göz, 2006). İlk ve acil yardım hizmetlerinde başarılı olmak öncelikle bu konuda iyi yetişmiş, yeterli sayıda insan gücünün varlığına bağlıdır.

İlk yardım bilgilerinin öğrenilmesinde nelerin yapılacağı kadar nelerin yapılmaması gerektiği de öğrenilmelidir (BüyükkayacıDuman, Koçak ve Sözen, 2013). Sağıı Bakanlığı Temel Sağlık Hizmetleri Müdürlüğü Illk yardım Yönetmeliğine göre tüm kurumlarda yirmi kişide bir, riskli işyerlerinde ise on kişiden bir kişinin ilk yardım eğitimi alması zorunlu kılınmıştır. Kazaları önlemenin en güvenilir yolu eğitimdir. Toplumun ilk yardım konusunda eğitilmesinin yararlarını ortaya koyan çalışmalar alanyazında yer almaktadır (Bayraktar ve Çelik, 2000). Kendisinin ve toplumun problemlerini çözebilecek, öğrencilerini yetiştirecek öğretmenlerin ilk yardım konusuna özel önem vermeleri önemlidir (Bozkurt vd., 2015). Bu doğrultuda, özellikle meslek yaşamları gereği ilk yardım uygulamaları ile karşılaşma olasıllğı yüksek olan ve bu uygulamaları doğru yapması beklenen alanlarda eğitim gören üniversite öğrencilerinin, bu konudaki bilgi ve becerilerinin yeterli ve güncel olması oldukça önemlidir (Altındiş vd., 2017). Bununla birlikte alanyazında yapılmış çalışmalar incelendiğinde ülkemizde üniversitelerin eğitim fakültelerinde öğrenim gören öğretmen adaylarının ilk yardım uygulayabilecek yeterli ve güncel bilgi ve beceriye sahip olup olmadıkları konusunda sınırlı sayıda çalışma olduğu görülmektedir. Bu araştırma, eğitim fakültelerinde öğrenim gören öğretmen adaylarının ilk yardım bilgi düzeylerini ortaya koymak amacıyla yapılmış ve bu açıdan alanyazına katkı sağlayabilecek bir çalışmadır.

\section{Araştırmanın Önemi}

Kalabalık öğrenci ve personel gurubunun toplu halde bir arada yaşadığı bir ortam olan okullarda gerekli önlemler alınmaz ise istenmeyen kazalar ve sakatlıklar görülebilir. Okullarda sık görülebilen kanama, solunum yetmezliği, bayılma, konvülsiyon, alerjik reaksiyonlar, yanıklar, zehirlenmeler, kafa travmaları, üst solunum yolu enfeksiyonları, deri enfeksiyonları, ishal, kusma, karın ağrısı, burkulma, kırık ve çıkık gibi ani durumlarda ilk yardıma gereksinim duyulmaktadır (Şahin, 2000). Okullarda öğretmenler istenmeyen bu kaza ve sakatlıklarda sağlık ekibinin bir parçası gibi danışmanlık, eğitim ve gözlem gibi etkinliklerde çok önemli rol oynarlar. Çünkü öğrencilerle uzun süre birlikte olmaktadırlar (Aksayan vd., 1998; Erkan ve Göz, 2006; Kibble, 1999; Kingma ve Henk-Jan, 2000). Ayrıca, öğrenciler okula ulaşımlarını sağlayan servis araçlarında da kazalara maruz kaldıkları gibi (West, 1996; Budge, 1998), laboratuvar çalışmalarında da çeşitli kazalar olabilmektedir (Kauffman, 2002; Hoff, 2003; Erkan ve Göz, 2006). ilkkyardım uygulamaları konusunda yapılan çalışmaların sonuçları, ilk yardım eğitiminin önemini ve gerekliliğini vurgulamaktadır

| Kastamonu Eğitim Dergisi, 2020, Vol. 28, No. 4| 
(Aydınlık, 2019; Altındiş vd., 2017; Deniz-Öztürk, 2018; Yüksel, 2019). İlk yardım uygulamalarının zamanında, doğru ve güncel bilgiler ışığında olması da son derece önemlidir (Kızıl vd., 2018). Ayrıca ilk yardım uygulamalarında kişilerin kendilerini yeterli hissetme durumlarının da önemli olduğu yapılan çalışmalarla ortaya konulmuştur. Bu çalışmaların sonuçları örneklem gruplarının genellikle kendilerini yeterli bulmadıkları (Özçelikay, Şimşek ve Asil, 1996; Polat ve Turacı, 2003) ya da kendilerini yeterli hissedenlerin oranlarının düşük seviyede olduğu yönündedir (Altındiş vd., 2017; Dinçer, Atakurt ve Şimşek, 2000; Sönmez vd., 2014; Yürümez vd., 2007).

Bu araştırmada, Kastamonu Üniversitesi Eğitim Fakültesi'nde öğrenim gören öğretmen adaylarının, ilk yardım bilgi düzeylerinin belirlenmesi ve elde edilen bilgiler ışığında durum hakkında betimleyici çıkarımların ortaya konulması amaçlanmıştır.

\section{YÖNTEM}

Bu bölümde, araştırmanın modeli, katılımcılar, veri toplama aracı, bu aracın geliştirilme ve uygulanma süreci ve elde edilen verilerin analizinde kullanılan istatistiksel analiz teknikleri başlıklar halinde sunulmuştur.

\section{Araştırmanın Modeli}

Kastamonu Üniversitesi Eğitim Fakültesinde öğrenim gören öğretmen adaylarının ilk yardım bilgi düzeyleri nicel veri toplama araçlarından anket yöntemiyle toplanmıştır. Bu tür araştırmalarda anket yoluyla geniş bir örneklem grubunun araştırma konusuyla ilgili düşüncesini belirlemek mümkündür. Bu araştırma, tarama modelinin kullanıldığı betimsel nitelikte bir çalışmadır. Tarama modeli, geçmişte ya da halen var olan bir durumu olduğu şekliyle betimlemeyi amaçlayan araştırmalardır. Araştırmaya konu olan olay, kendi koşulları içinde ve olduğu gibi tanımlanmaya çalışılır (Karasar, 2012).

\section{Katılımcılar}

Araştırmaya, Kastamonu Üniversitesi Eğitim Fakültesi bilgisayar ve öğretim teknolojileri, fen bilgisi, ilköğretim matematik, müzik, okul öncesi (I. ve II. öğretim), resim iş, sınıf, sosyal bilgiler, Türkçe ve psikolojik danışmanlık ve rehberlik öğretmenliği programlarında öğrenim gören 1443'ü kadın, 595'i erkek olmak üzere toplam 2038 öğretmen adayı katılmıştır. Katılımcıların cinsiyet ve öğretmenlik programlarına göre dağılımı Tablo 1'de verilmiştir.

Tablo 1. Katılımcıların program ve cinsiyet dağılımları

\begin{tabular}{|c|c|c|c|c|c|c|}
\hline \multirow{2}{*}{ Program } & \multicolumn{2}{|c|}{ Kadın } & \multicolumn{2}{|c|}{ Erkek } & \multicolumn{2}{|c|}{ Toplam } \\
\hline & $\mathrm{f}$ & $\%$ & $f$ & $\%$ & $f$ & $\%$ \\
\hline Bilgisayar ve Öğretim Teknolojileri Öğretmenliği & 39 & 39,39 & 60 & 60,61 & 99 & 4,86 \\
\hline Fen Bilgisi Öğretmenliği & 181 & 74,49 & 62 & 25,51 & 243 & 11,92 \\
\hline Illköğretim Matematik Öğretmenliği & 146 & 71,92 & 57 & 28,08 & 203 & 9,96 \\
\hline Müzik Öğretmenliği & 32 & 59,26 & 22 & 40,74 & 54 & 2,65 \\
\hline Okul Öncesi Öğretmenliği (Birinci Öğretim) & 201 & 88,16 & 27 & 11,84 & 228 & 11,19 \\
\hline Okul Öncesi Öğretmenliği (İkinci Öğretim) & 192 & 81,36 & 44 & 18,64 & 236 & 11,58 \\
\hline Psikolojik Danışmanlık ve Rehberlik Öğretmenliği & 59 & 64,13 & 33 & 35,87 & 92 & 4,51 \\
\hline Resim İş Öğretmenliği & 60 & 68,18 & 28 & 31,82 & 88 & 4,32 \\
\hline Sınıf Öğretmenliği & 242 & 75,86 & 77 & 24,14 & 319 & 15,65 \\
\hline Sosyal Bilgiler Öğretmenliği & 130 & 53,28 & 114 & 46,72 & 244 & 11,97 \\
\hline Türkçe Öğretmenliği & 161 & 69,40 & 71 & 30,60 & 232 & 11,38 \\
\hline Toplam & 1443 & 70,80 & 595 & 29,20 & 2038 & 100,00 \\
\hline
\end{tabular}

Tablo 1'e göre en çok katılımcı okul öncesi öğretmenliği (I. ve II. öğretim) programı, en az katılımcı ise 54 öğretmen adayı ile müzik öğretmenliği programı olmuştur. Katılımcıların öğrenim gördükleri sınıf seviyelerine göre dağılımları ise Tablo 2'de verilmiştir.

Tablo 2. Katılımcıların sınıf seviyeleri

\begin{tabular}{cccc}
\hline Sinıf Seviyesi & $f$ & $\%$ & 21,7 \\
\hline 1. & 443 & 26,4 & 28,1 \\
2. & 538 & 23,8 & 100 \\
3. & 572 & 485 & \\
\hline Toplam & 2038 & & 100 \\
\hline
\end{tabular}

Tablo 2'ye göre, katılımcıların en fazla olduğu sınıf seviyesi \%28,1 öğretmen adayı ile üçüncü sınıflar, en az olduğu sınıf seviyesi ise \%21,7 öğretmen adayı ile birinci sınıflardır. 


\section{Veri Toplama Aracı}

Araştırmada, öğretmen adaylarına iki bölümden oluşan bir anket uygulanmıştır. Anketin ilk bölümü bağımsız değişkenleri gösteren tanıma ve ilk yardım eğitimi alma durumları ve düşünceleri ile ilgili sorulardan, ikinci bölümü ise ilk yardım hakkında bilgi içeren 23 adet çoktan seçmeli sorudan oluşmaktadır. Araştırmada kullanılan anket; Bozkurt vd. (2015) tarafından hazırlanmış, geçerlik ve güvenirlik çalışmaları yapılarak Cronbach Alpha iç tutarılıı katsayısı 0,62 olarak bulunmuş ve gerekli izin alınarak araştırmada kullanılmıştır.

\section{Uygulama Süreci}

Kastamonu Üniversitesi Eğitim Fakültesinde öğrenim gören öğretmen adaylarının bu araştırmaya katılabilmesi için gerekli izinler alınmış ve gönüllülük çerçevesi içinde her bir öğretmen adayına Kastamonu Üniversitesi Öğrenci Bilgi Sistemi https://obs.kastamonu.edu.tr adresinden ulaşılmıştır. Araştırma için veriler, 23.03.2018-16.04.2018 tarihleri arasında anket yöntemi ile toplanmışır. Öğretmen adaylarına anketteki soruları cevaplamaları için 30 dakika süre verilmiştir. Araştırmaya katılan öğretmen adaylarının anketteki sorulara verdikleri cevapların sadece bu araştırma için kullanılacağı, bireysel değerlendirme yapılmayacağı ve cevapların araştırmacılar dışında herhangi biri tarafından görülmeyeceği belirtilerek anketteki sorulara objektif cevaplar vermeleri ve böylece elde edilen verilerin daha da gerçeği yansıtması sağlanmıştır.

\section{Verilerin Analizi}

Elde edilen verilerin değerlendirmesinde tanımlayıcı istatistik (frekans-yüzde) kullanılmıştır.

\section{BULGULAR}

Bu bölümde, çalışmanın amacı doğrultusunda öğretmen adaylarına uygulanan anketten elde edilen verilerin bulguları tablolar halinde düzenlenmiş ve yorumlanmıştır. Ankette öğretmen adaylarına, "ilk yardım eğitimi aldııı mı?" ve "Sizce ilk yardım eğitimi gerekli midir?" soruları yöneltilmiş ve bu surlara ilişkin vermiş oldukları cevapların frekans ve yüzde değerleri Tablo 3'te verilmiştir.

Tablo 3. Öğretmen adaylarının ilk yardım eğitimi alma durumları ve konuya ilişkin düşünceleri

\begin{tabular}{lcccc}
\hline & & Evet & Hayır & Toplam \\
\hline Daha önce ilk yardım eğitimi alma & $\mathrm{f}$ & 1157 & 863 & 2020 \\
durumu & $\%$ & 57 & 43 & 100 \\
Illk yardım eğitiminin gerekli olup & $\mathrm{f}$ & 1931 & 86 & 2017 \\
olmaması & $\%$ & 96 & 4 & 100 \\
\hline
\end{tabular}

Tablo 3'e göre öğretmen adaylarının \%57'si daha önce ilk yardım eğitimi aldığıı, \%43'ü ise ilk yardım konusunda eğitim almadığını belirtmiştir. Ayrıca, öğretmen adaylarının \%96'sı gibi büyük bir çoğunluğu ilk yardım eğitiminin gerekli olduğunu ifade ederken, \%4 gibi küçük bir oranda ise ilk yardım eğitiminin gerekli olmadığı yönünde görüş bildirmişlerdir.

Araştırmada öğretmen adaylarına sorulan diğer bir soru ise "ilk yardım eğitimini nereden aldınız?" sorusudur. Öğretmen adaylarının bu soruya vermiş oldukları cevapların frekans ve yüzde değerleri Tablo 4'te verilmiştir.

Tablo 4. Illk yardım eğitimi alan öğretmen adaylarının ilk yardım eğitimi alma durumları

\begin{tabular}{lcc}
\hline İlk yardım eğitimi alma türü & $\mathrm{f}$ & $\%$ \\
\hline Ders olarak & 799 & 69 \\
Ehliyet kursunda & 358 & 31 \\
\hline Toplam & 1157 & 100 \\
\hline
\end{tabular}

Tablo 4'e göre, öğretmen adaylarının \%69'u, ilk yardım eğitimini ders olarak, \%31'i ise ehliyet kursunda aldıklarını ifade etmişlerdir. Araştırmaya katılan öğretmen adaylarının cinsiyetlerine göre anketteki bilgi sorularına verdikleri cevaplar doğrultusunda ilk yardım başarı frekans ve yüzde değerleri Tablo 5 'te verilmiştir. 
Tablo 5. Öğretmen adaylarının ilk yardım testi başarılarının cinsiyete göre değişimi

\begin{tabular}{|c|c|c|c|c|c|c|}
\hline Sorular & $\begin{array}{l}\text { Kadın } \\
\text { (f) }\end{array}$ & $\begin{array}{c}\text { Kadın } \\
\text { Başarı (\%) }\end{array}$ & $\begin{array}{l}\text { Erkek } \\
\text { (f) }\end{array}$ & $\begin{array}{c}\text { Erkek } \\
\text { Başarı (\%) }\end{array}$ & $\begin{array}{l}\text { Toplam } \\
\text { (f) }\end{array}$ & $\begin{array}{c}\text { Genel } \\
\text { Başarı (\%) }\end{array}$ \\
\hline 1. Sizce ilk yardım nedir? & 1251 & 71,28 & 504 & 28,72 & 1755 & 87 \\
\hline 2. Sizce hangisi ilk yardımın öncelikli hedeflerindendir? & 689 & 71,40 & 276 & 28,60 & 965 & 48 \\
\hline $\begin{array}{l}\text { 3. Sizce Epilepsi (Sara) komasına giren bir çocuğa ilk müdahale } \\
\text { nasıl yapılır? }\end{array}$ & 1017 & 74,02 & 357 & 25,98 & 1374 & 72 \\
\hline $\begin{array}{l}\text { 4. Türkiye'de hastanın en yakın sağlık kuruluşuna sevkini } \\
\text { sağlamak amacıyla hangi telefon numarası aranmalıdır? }\end{array}$ & 1274 & 71,53 & 507 & 28,47 & 1781 & 92 \\
\hline 5. Sizce yanıklarda ilk yardım nasıl yapılır? & 752 & 78,01 & 212 & 21,99 & 964 & 54 \\
\hline $\begin{array}{l}\text { 6. Bir insanın normal vücut sıcaklığı koltuk altından } \\
\text { ölçüldüğünde kaç Santigrat derecedir? }\end{array}$ & 882 & 73,20 & 323 & 26,80 & 1205 & 66 \\
\hline $\begin{array}{l}\text { 7. Aşağıdaki şıklardan hangisinde, vücutta nabız alınabilen bölge } \\
\text { doğru olarak verilmiştir? }\end{array}$ & 810 & 73,70 & 289 & 26,30 & 1099 & 63 \\
\hline $\begin{array}{l}\text { 8. Sizce sıcak çarpması geçiren bir çocuğa ilk olarak ne } \\
\text { yapılmalıdır? }\end{array}$ & 988 & 76,06 & 311 & 23,94 & 1299 & 78 \\
\hline $\begin{array}{l}\text { 9. Sizce ilk yardım uygulaması sırasında solunum yolu açıkığı } \\
\text { nasıl sağlanır? }\end{array}$ & 566 & 71,65 & 224 & 28,35 & 790 & 49 \\
\hline 10. Sizce çocuklarda solunum varlığı nasıl değerlendirilir? & 827 & 74,24 & 287 & 25,76 & 1114 & 71 \\
\hline 11. Sizce yabancı cisim batmasında uygulanacak yöntem nedir? & 367 & 74,44 & 126 & 25,56 & 493 & 32 \\
\hline 12. Sizce ilk yardımda vücut sıcaklığı nereden alınır? & 656 & 74,04 & 230 & 25,96 & 886 & 57 \\
\hline $\begin{array}{l}\text { 13. Sizce çocuklarda kalp-akciğer canlandırması uygulaması } \\
\text { sırasında verilmesi gereken soluk ile kalp masajı sayısı ne } \\
\text { olmalıdır? }\end{array}$ & 273 & 73,98 & 96 & 26,02 & 369 & 25 \\
\hline 14. Sizce zehirlenmede ilk yapılması gereken nedir? & 263 & 67,96 & 124 & 32,04 & 387 & 25 \\
\hline 15. Sizce hangisi kırık belirtisidir? & 623 & 74,43 & 214 & 25,57 & 837 & 55 \\
\hline $\begin{array}{l}\text { 16. Sizce hangisi bayılmada yapılan ilk yardım uygulamalarından } \\
\text { değildir? }\end{array}$ & 478 & 72,75 & 179 & 27,25 & 657 & 44 \\
\hline 17. Sizce çocuklarda bilinç kontrolü nasıl yapılır? & 176 & 65,43 & 93 & 34,57 & 269 & 19 \\
\hline 18. Sizce çocuklarda tek ilk yardımcı varsa 112 ne zaman aranır? & 171 & 68,95 & 77 & 31,05 & 248 & 17 \\
\hline 19. Sizce bilinci kapalı bir çocukta ilk olarak ne yapılmalıdır? & 408 & 77,13 & 121 & 22,87 & 529 & 36 \\
\hline $\begin{array}{l}\text { 20. Sizce çocuklarda solunum yoluna yabancı cisim kaçmasında } \\
\text { tam tıkanma varsa ne yapııır? }\end{array}$ & 658 & 74,52 & 225 & 25,48 & 883 & 59 \\
\hline $\begin{array}{l}\text { 21. Sizce kanamayı durdurmak için ilk yardımcının ilk yapması } \\
\text { gereken aşağıdakilerden hangisidir? }\end{array}$ & 453 & 74,02 & 159 & 25,98 & 612 & 40 \\
\hline 22. Sizce el ve ayak kopmalarında kopan parça ne yapılmalıdır? & 454 & 77,61 & 131 & 22,39 & 585 & 38 \\
\hline 23. Sizce burun kanamasında ilk yardımda ne yapılmalıdır? & 574 & 74,55 & 196 & 25,45 & 770 & 50 \\
\hline
\end{tabular}

Tablo 5'te yer alan 23 adet çoktan seçmeli soru araştırmaya katılan öğretmen adaylarına sorulmuş ve öğretmen adaylarının bu sorulara verdikleri doğru cevapların yüzde değerleri gösterilmiştir. Tablo 5'e göre, araştırmaya katılan kadın öğretmen adayları $\% 71,53$ 'ü, 4. soruyu en büyük oranda doğru cevaplarken, erkek öğretmen adayları ise $\% 28,47$ 'si aynı soruya en büyük oranda doğru cevap vermişlerdir. Kadın öğretmen adaylarının \%68,95’i en az oranda 18. soruya doğru cevap verirken, erkek öğretmen adaylarının ise \%31,05'i aynı soruya en az oranda doğru cevap vermişlerdir. Verilere göre kadın öğretmen adaylarının ( $\bar{X}=635,22)$ ilk yardım bilgisi, erkek öğretmen adaylarına $(\bar{X}=228,74)$ göre daha fazla olduğu tespit edilmiştir.

11 öğretmenlik programında öğrenim gören öğretmen adaylarının bu programlara göre ilk yardım testi başarı puanlarına ait her bir soru için frekans ve yüzde değerleri Tablo 6 'da verilmiştir. 


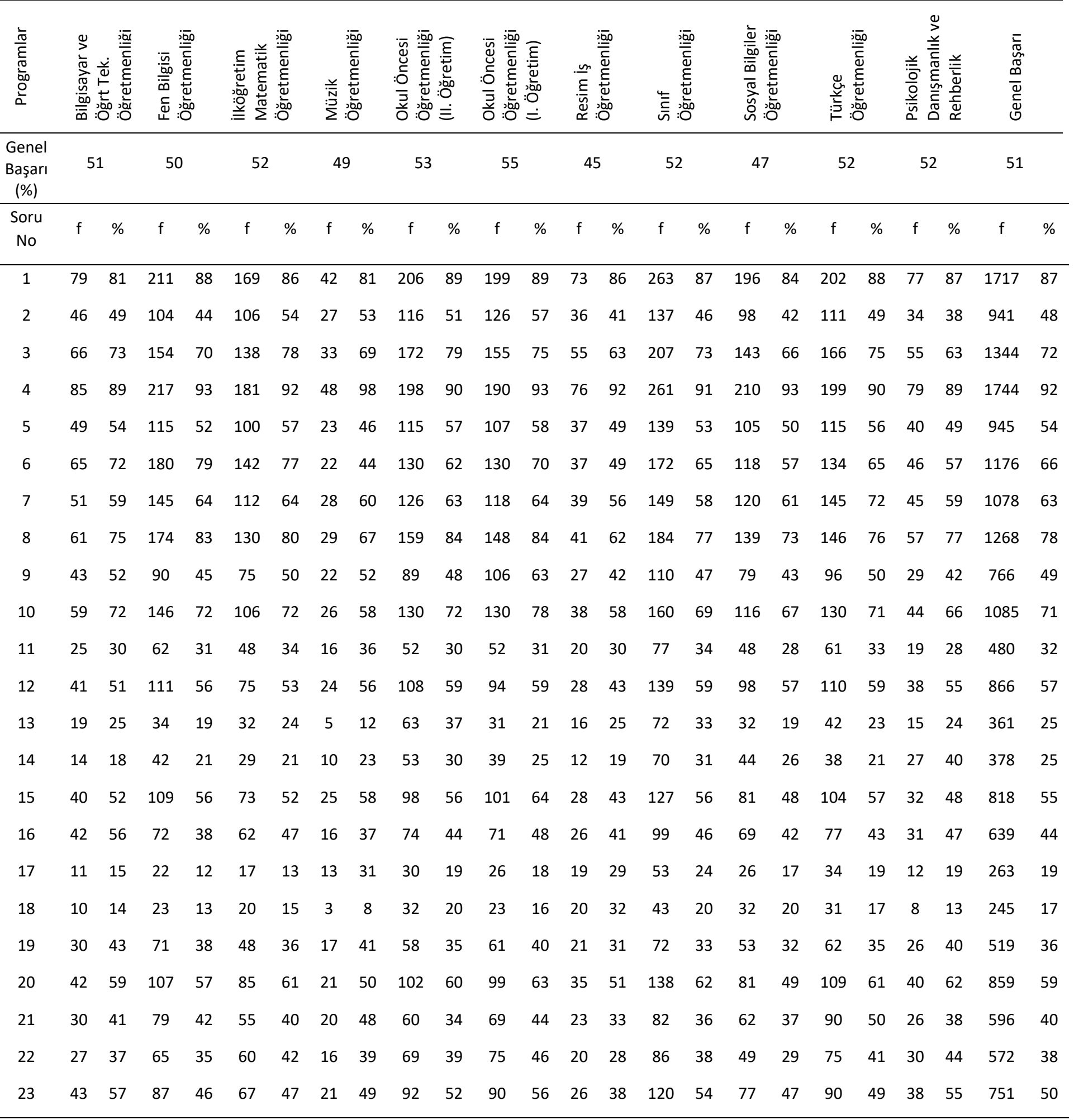

Tablo 6’ya göre, öğretmen adaylarının okudukları tüm öğretmenlik programlarına göre ilk yardım bilgisi genel başarıları \%51 olarak hesaplanmıştır. Her bir öğretmenlik programına göre başarı yüzdeleri \%45 ile \%55 arasında değişmektedir. En düşük ilk yardım bilgisi ortalama başarı değeri \%45 ile resim iş öğretmenliği programında iken, en başarılı öğretmenlik programı \%55 ile okul öncesi öğretmenliği (I. öğretim) olmuştur. Bu programı, \%53 ile okul öncesi öğretmenliği (Il. öğretim), \%52 ile Türkçe, psikolojik danışmanlık ve rehberlik ve ilköğretim matematik öğretmenlikleri takip etmektedir. Araştırmaya katılan öğretmen adaylarına sorulan sorulardan biri "Türkiye'de hastanın en yakın sağlık kuruluşuna sevkini sağlamak amacıyla hangi telefon numarası aranmalıdır?” sorusudur. Bu soruyu, en büyük oranda sınıf öğretmenliğinde öğrenim gören 261 (\%91) öğretmen adayları doğru cevaplamışlardır. Araştırmada öğretmen adaylarına sorulan diğer bir soru ise, "Sizce çocuklarda tek ilk yardımcı varsa 112 ne zaman 
aranır?" sorusudur. Bu soruyu en düşük oranda müzik öğretmenliğinde okuyan 3 (\%8) öğretmen adayı doğru cevaplamıştır. Bunun sebebi, sınıf öğretmenliği programında okuyan öğretmen adaylarının ilk yardım dersini almaları, müzik öğretmenliği programında öğrenim gören öğretmen adaylarının ise böyle bir dersle karşılaşmamaları olabilir.

\section{TARTIŞMA}

Bu araştırmada; Kastamonu Üniversitesi Eğitim Fakültesindeki öğretmenlik programlarında öğrenim gören öğretmen adaylarının ilk yardım bilgi düzeylerinin tespit edilmesi amaçlanmış ve bu amaç doğrultusunda 2038 öğretmen adayına ilk yardım bilgi sorularını içeren bir anket uygulanmıştır. Ayrıca araştırmaya katılan öğretmen adaylarının ilk yardım bilgi düzeylerinin cinsiyete ve okudukları programa göre nasıl değiştiğine de bakılmış ve elde edilen sonuçlar tartışılmıştır.

Elde edilen sonuçlara göre, öğretmen adaylarının yarıdan fazlası ilk yardım eğitimi aldıklarını beyan etmelerine karşın solunum, zehirlenme, bayılma ve bilinç kaybı, kanama ve uzuv kopması gibi hayati açıdan kritik hususlarda bilgi düzeylerinin \%50'nin altında kaldığı tespit edilmiştir. Bunun yanında, öğretmen adaylarının \%96’sı ise ilk yardım eğitiminin gerekli olduğunu belirtmişlerdir. Eğitim kurumlarında ilk yardım müdahalesinde bulunacak kişiler arasında ilk sıralarda yer alacak olan öğretmen adaylarının daha önce ilk yardım eğitimi almış olmalarına karşın temel ilk yardım düzeyindeki bilgilerinin düşük olmasının itina ile üzerinde durulması gereken bir husus olduğu düşünülmektedir. Benzer çalışmalarda da bu durumdan bahsedilmiştir (Bozkurt vd., 2015; Erkan ve Göz, 2006; Bayraktar ve Çelik, 2000; Amro ve Qtait, 2017; Gowri ve Missiriya, 2017; Karadağ-Arlı ve Yıldırım, 2017; Özyürek vd., 2013). Amro ve Qtait (2017) çalışmalarında, sekiz okuldan 150 öğretmene anket uygulamışlar ve elde ettikleri sonuçlara göre, öğretmenlerin ilk yardım puan ortalamasını \%71,41 olarak bulmuşlardır. Araştırmaya katılan öğretmenlerin çoğunun, diyabetik hastalar için dengeli beslenmenin ve uygun hipoglisemi tedavisinin doğru olduğunu bildiklerini belirtmişlerdir. Gowri ve Missi-riya (2017) çalışmalarında, öğrencilerin sağlık bakımı üzerine öğretmenlerinin uygulama ve bilgi düzeylerini belirlemek için, Hindistan'ın Chennai, Thiruvellore ve Kancheepuram şehirlerinde rastgele okullarda çalışan 900 öğretmene anket uygulamışlardır. Çalışmalarının sonucunda, araştırmaya katılan öğretmenlerin \%78'inin sağlık bakımı üzerine yeterli bilgiye sahip olmadıklarını belirlemişlerdir. Karadağ-Arlı ve Yıldırım (2017) çalışmalarında, öğretmenlerin ilk yardım bilgilerine temel ilk yardım eğitiminin etkilerini incelemişlerdir. Ön-test ve son-test grupları arasında ilk yardım bilgi düzeylerine göre önemli bir farklılık olduğunu bulmuşlardır. Araştırmanın bu sonucu, ilk yardım eğitimi verilen deneysel gruplarda eğitimin etkili olduğunu göstermiştir. Özyürek vd., (2013) çalışmalarında, Afyonkarahisar il merkezinde görev yapan lise öğretmenlerine iki gün temel ilk yardım bilgileri ve temel yaşam desteği konularında görsel ve uygulamalı eğitim vermişlerdir. Eğitim öncesi ve eğitim sonrası katılımcılara 33 soruluk bir anket uygulaması yapmışlar ve elde ettikleri verilerin analizinde, t-testi ve ANOVA testi uygulamışlardır. Araştırmalarının sonucunda, öğretmenlerin aldıkları son-test puan ortalamasının $(80,52)$, ön-test puan ortalamasından $(48,51)$ daha yüksek olduğunu ve aralarında istatistiki olarak anlamlı bir fark olduğunu tespit etmişlerdir.

Araştırmaya katılan öğretmen adaylarının ilk yardım bilgi düzeyleri cinsiyet bakımından incelenmiş ve kadın öğretmen adaylarının bilgi düzeylerinin erkek öğretmen adaylarına nazaran daha yüksek olduğu görülmüştür. Bu farkın nedeni, kadınların günlük yaşamlarında erkeklere göre daha fazla ilk yardım gerektiren durumlarla karşılaşmalarından kaynaklandığı düşünülebilir (Saruhan vd., 2018). Nayır, Uskun ve Türkoğlu (2011) tarafından yapılan çalışmada, kadınların ilk yardım bilgi puan ortalamaları erkeklerin ilk yardım bilgi puan ortalamalarından anlamlı olarak daha yüksek bulunmuştur. Alanyazında yapılmış benzer çalışmalardan Koç (1994)'un ve Savaşer (2001)'in araştırmalarında, kadınlar ile erkeklerin ilk yardım bilgi puanları arasındaki fark istatistiksel olarak anlamlı bulunmuştur. Alanyazında yapılmış benzer çalışmalar incelendiğinde bulunan sonuçların, bu araştırmanın sonuçlarıyla uyumlu olduğu söylenebilir.

Araştırmaya katılan öğretmen adaylarının okudukları programa göre, ilk yardım bilgisi başarı puanları en fazla okul öncesi öğretmenliği programında okuyan öğretmen adaylarında görülmüştür. Bunun sebepleri arasında; Okul Öncesi Öğretmenliği Programı'nda ilk yardım dersinin olması ve öğretmen adaylarının ileride öğretmen olduklarında daha küçük yaşlardaki çocuklarla ilgilenecek olmaları ve bu yaşlardaki çocuklarda yaralanmaların ve çeşitli hastalıkların daha sık görülmesinden dolayı ilk yardım eğitimine daha önem vermeleri olabilir. Ayrıca, 2013 ve yenilenen 2018 Okul Öncesi Eğitimi Programlarında ilk yardımla ilgili zorunlu bir dersin olması da, onların ilk yardım başarı puanlarının yüksek olmasında etkili olmuş olabilir. Bunun yanında, diğer öğretmenlik programlarından sınıf öğretmenliğinde okuyan öğretmen adaylarının başarı puanları da genel ortalamanın üstünde çıkmıştır. Bunun sebebi 2013 Sını Öğretmenliği Programı’nda sekizinci yarıyılda "trafik ve ilk yardım" adında zorunlu bir dersin olması ve son sınıfta okuyan öğretmen adaylarının bir dönem boyunca bu dersi okumuş olmaları olabilir. Öğretmen adaylarının ilk yardım bilgisi ile ilgili özellikle dış kanama, kırık, travma, epilepsi, diyabet ve yanma gibi durumlarda daha fazla eğitime ihtiyaçları bulunmaktadır. Çünkü öğretmen olduklarında kendi öğrencilerinde en sık karşılaşabilecekleri ve ilk yardım gerektiren durumlardandır.

\section{SONUÇ VE ÖNERILER}

Araştırma sonucunda, öğretmen adaylarının ilk yardımla ilgili yeterli bilgilere sahip olmadıkları ve bu eksikliklerinin de farkında oldukları tespit edilmiştir. Ayrıca, öğretmen adayları ilk yardımla ilgili eksikliklerini gidermek için eğitime ihtiyaçlarının olduğunu belirtmişlerdir. Eğitim fakültesi lisans programları incelendiğinde; 2013 Programında sadece sınıf, okul öncesi ve psikolojik danışmanlık ve rehberlik öğretmenliklerinde ilk yardımla ilgili dersler bulunmaktadır. Bu programda; sınıf öğretmenliği sekizinci 
yarıyılda "trafik ve ilk yardım" adı altında, okul öncesi öğretmenliğinde ikinci yarıyılda "anne-çocuk sağlığı ve ilk yardım" adı altında zorunlu bir ders olarak bulunmaktadır. Psikolojik danışmanlık ve rehberlik öğretmenliğinde ise seçmeli sağıı bilgisi ve ilk yardım dersi bulunmaktadır (MEB, 2013). Diğer öğretmenlik programlarında ilk yardımla ilgili bir ders bulunmamaktadır. Yenilenen 2018 Programında ise, sadece okul öncesi öğretmenliği birinci yarıyılda "çocuk sağlığı ve ilk yardım" adında zorunlu bir ders olarak konulmuştur. Bunun yanında, bilgisayar ve öğretim teknolojileri öğretmenliğinin ikinci yarıyılında da elektronik devre elemanları dersi içerisinde "elektrik kazalarına karşı korunma ve ilk yardım" konusu geçmektedir. Diğer öğretmenlik programlarına ilk yardım dersi zorunlu bir ders olarak konulmamıştır. Bunun yerine, 2018 Öğretim Programı́nda eğitim fakültelerinin öğretmenlik programlarına seçmeli olarak konulan "beslenme ve sağılk” dersi içinde ilk yardım konusu geçmektedir (MEB, 2018).

İlk yardım eğitimi, eğitim fakültelerindeki tüm öğretmenlik programları için zorunlu olması, bu eğitimin düzenli aralıklarla güncellenmesi ve öğrencilerin programda belirtilen amaçlara yönelik davranışlar kazanmalarını, temel bilgi ve beceriler edinmelerini sağlayıcı nitelikte olması önerilmektedir.

\section{KAYNAKÇA}

Akdemir, N., \& Birol, L. (2005). iç hastalıkları ve hemşirelik bakımı. Sistem Ofset, Ankara.

Aksayan S, Bahar Z, Bayık A ve ark. (1998). Halk sağlığı hemşireliği el kitabı. Erefe, i̇. (Ed), Vehbi Koç yayınları, No. 14: İstanbul.

Altındiş, S., Tok, Ş., Aslan, F. G., Pilavcı-Adıgül, M., Ekerbiçer, H. Ç., \& Altındiş, M. (2017). Üniversite öğrencilerinin ilk yardım bilgi düzeylerinin değerlendirilmesi. Sakarya Tıp Dergisi, 7(3), 125-130.

Amro, N. R., \& Qtait, M. (2017). General knowledge \& attitude of first aid among school teacher's in palestine international. Journal of Innovative Research in Medical Science (IJIRMS), 2(4), 660-665.

Ateş, Ç. (2005). Gaziantep ili merkeze bağlı ilköğretim okullarında çalışan öğretmenlerin ilk yardım uygulamalarına ilişkin bilgi düzeylerinin belirlenmesi. Yüksek lisans tezi, Gaziantep Üniversitesi Sağlık Bilimleri Enstitüsü, Gaziantep.

Aydınlık, C. (2019). İstanbul'un bağcılar ilçesinde çalışmakta olan beden eğitimi öğretmenlerinin ilk yardım bilgi düzeylerinin karşılaştırılması. Yüksek lisans tezi, İstanbul Gelişim Üniversitesi Sağlık Bilimleri Enstitüsü, İstanbul.

Aytaç, Ş., Gürleyen-Gök, M., \& Özkan S. (2016). Bir işçi sağlığı ve güvenliği uygulaması olan temel ilk yardım eğitiminin incelenmesi. Gazi Medical Journal, 27(2), 53-57.

Bayraktar, N., \& Çelik, S. (2000). Ankara'daki taksi şoförlerinin ilk yardım konusundaki bilgi gereksinimleri. Sağlık ve Toplum, 10(2), 55-61.

Beyazova, U., \& Güler, Ç. (1991). Çocuk sağlığı ve gelişimi. Hatipoğlu Yayınları, Ankara.

Bozkurt, A., Özbar, N., Çekiç, S., Küçük-Yetgin, M., \& Özmerdivenli, R. (2015). Sınıf öğretmenleri ve branş öğretmenlerinin ilk yardım bilgi düzeylerinin tespit edilmesi. Uluslararası Hakemli Ortopedi Travmatoloji ve Spor Hekimliği Dergisi, 2(3), 1-10.

Budge, D. (1998). Parents share blame for poor road safety of pupils. Times Educational Supplement, 1, 27-8.

Büyükkayacı-Duman, N., Koçak, C., \& Sözen, C. (2013). Üniversite öğrencilerinin ilk yardım bilgi düzeyleri ve bunu etkileyen faktörler. Hitit Üniversitesi Sosyal Bilimler Enstitüsü Dergisi, 6(1), 57-70.

Deniz-Öztürk, Y. (2018). Niğde Ömer Halisdemir üniversitesi sınıf öğretmenliği bölümü öğrencileri ve Niğde merkez okullarındaki sınıf öğretmenlerinin ilk yardım konusundaki bilgi düzeylerinin karşılaştırılması. Yüksek lisans tezi, Niğde Ömer Halisdemir Üniversitesi Eğitim Bilimleri Enstitüsü, Niğde.

Dinçer, Ç., Atakurt, Y., \& Şimşek, I. (2000). Okulöncesi eğitimcilerinin ilk yardım bilgi düzeyleri üzerine bir araştırma. Ankara Üniversitesi Tıp Fakültesi Mecmuası, 53(1), 31-38.

Erkan, M., \& Göz, F., (2006). Öğretmenlerin ilk yardım konusundaki bilgi düzeylerinin belirlenmesi. Atatürk Üniversitesi Hemşirelik Yüksekokulu Dergisi, 9(4), 63-68.

Gowri, M., \& Missiriya, S., (2017). Knowledge and practice of school teachers on health care of school children. International Journal of Pharma and Bio Sciences, 8, 21-32.

Hoff, D. J. (2003). Science-lab safety upgraded after mishaps. Education Week, 22(33), 1-4.

Karadağ-Arlı, Ş., \& Yıldıım, Z. (2017) The effects of basic first aid education on teachers' knowledge level: A pilot study. International Journal of Caring Sciences, 10(2), 813-818.

Karasar, N. (2012). Bilimsel araştırma yöntemi. Nobel Akademi, Ankara.

Kauffman, J. A. (2002). How safe is your science lab? District Administration, 38(10), 8-10.

Kırılmaz, A. Y., \& Arısoy, M. (2002). Ev kazaları ve ilk yardım. Sağlık ve Toplum Dergisi, 4, 27-32. 
Kızıl, M., Üstünkarlı, N., Yıldız, Ş., Kurtel, K., Şemin, İ., \& Abacıoğlu, Y. H. (2018). İlkyardım bilgilerinin doğruluğu ve ilk yardım uygulamalarına etkisinin değerlendirilmesi. Hastane Öncesi Dergisi (HOD), 3(1), 15-30.

Kibble, D. G. (1999). A survey of LEA guidance and support for the management of crises in schools. School Leadership \& Management, 19(3), 373-85.

Kingma, J., \& Henk-Jan T., D. (2000). Injuries due to school sports accidents in 4 to 13-yr.-old children. Perceptual \& Motor Skills, 90(1), 319-326.

Kliegman, R., Behrman, R., Jenson, H., \& Stanton B. (2007). Nelson textbook of pediatrics, (18th edition). Saunders-Elsevier.

Koç, M. A. (1994). Bir grup hekim dışı sağlık personeli ile sağlık meslek lisesi son sınıf öğrencilerinin ilk yardım bilgi düzeylerinin ölçülmesi. Yüksek lisans tezi, Gazi Üniversitesi Sağlık Bilimleri Enstitüsü, Ankara.

Lingard, H. (2002). The effect of first aid training on Australian construction workers' occupational health and safety motivation and risk control behavior. Journal of Safety Research, 33, 209-230.

MEB (2013). Öğretim programları. Ankara.

MEB (2018). Öğretim programları. Ankara.

Nayır, T., Uskun, E., \& Türkoğlu, H. (2011). Isparta il merkezinde görevli öğretmenlerin ilk yardım bilgi düzeyleri ve tutumları. S.D.Ü. Tıp Fak. Dergisi, 18(4), 123-127.

Özçelikay, G., Şimşek, I., \& Asil, E. (1996). Üniversite öğrencilerinin ilk yardım konusundaki bilgi düzeyleri üzerine bir çalışma. Ankara Üniversitesi Eczacılık Fakültesi Dergisi, 25(2), 43-48.

Özyürek, P., Bayram, F., Beştepe, G., Ceylantekin, Y., Ciğerci, Y., Çelik, Y., Kuyucuoğlu, N., Karaca, Ş., Temel, S., \& Yılmazer, A. (2013). Lise öğretmenlerine verilen temel ilk yardım eğitiminin etkililiğinin değerlendirilmesi. Sosyal Bilimler Dergisi, 15(1), 183-198.

Polat, A., \& Turacı, G. (2003). Bir polis okulu öğrencilerinin ilk yardım konusundaki bilgi ve tutumları. Fırat Üniversitesi Tıp Fakültesi Halk Sağlığı ABD Dergisi, 2, 27-32.

Saruhan, Ç., Saruhan, R., Yıldırım, C., \& Ovayolu, N. (2018). Gaziantep ili devlet ilköğretim okullarında çalışan öğretmenlerin ilk yardım uygulamalarına ilişkin bilgi düzeylerinin belirlenmesi. Batman Üniversitesi Yaşam Bilimleri Dergisi, 8(1/2), 36-46.

Savaşer, F. (2001). Çankırı ilinde görev yapan hekim dışı sağlık personeli ile lise öğretmenlerinin ilk yardım konusundaki bilgi düzeylerinin karşılaştırılması. Yüksek lisans tezi, Ankara Üniversitesi Sağlık Bilimleri Enstitüsü, Ankara.

Singer, A. J., Gulla, J., Thode, H. C., \& Cronin, K. A. (2004). Pediatric first aid knowledge among parents. Pediatr Emerg Care, $20,808-811$.

Sönmez Y., Uskun E., \& Pehlivan A. (2014). Okul öncesi öğretmenlerinin temel ilk yardım uygulamalarına ilişkin bilgi düzeyleri, Isparta örneği. Türk Pediatri Arşivi, 49, 238-246.

Stone, K. E., Lanphear, B. P., Pomerantz, W .J., \& Khoury, J. (2000). Childhood injuries and deaths due to falls from windows. Journal of Urban Health, 77(1), 26-33.

Şahin, F. (2000). Okul sağlığı. Gazi Üniversitesi Tıp Fakültesi Çocuk Sağlığı ve Hastalıkları Ana Bilim Dalı Dergisi, 9(6), $210-212$.

T.C. Sağlık Bakanlığı (2008). Sağlık hizmetlerinde okul sağlığı kitabı. Yücel Ofset Matbaacılık, Ankara.

URL-1. Karayolu_Trafik_Kaza_ìstatistikleri Sayı: 2460621 Haziran 2017 Emniyet Genel Müdürlüğü Trafik Hizmetleri Başkanlığının verileri http://www.tuik.gov.tr/UstMenu.do?metod=temelist (Erişim tarihi: 15.05.2018)

URL-2. Türkiye İstatistik Kurumu (TUIK) verileri http://www.tuik.gov.tr/PreHaberBultenleri.do?id=24648 (Erişim tarihi: 15.05.2018).

West, D. (1996). Child's death raises doubt over private-school drivers' training. New York Times, 145(29), $18-20$.

Yüksel, N. (2019). Spor bilimleri fakültesi ve spor lisesi öğrencilerinin ilk yardım ve temel yaşam desteği hakkında bilgi beceri ve tutumlarının belirlenmesi. Yüksek lisans tezi, Ondokuz Mayıs Üniversitesi Sağlık Bilimleri Enstitüsü, Samsun. 